\title{
テラヘルツ量子カスケードレーザーを用いた半導体磁気光学
}

\author{
河野 淳一郎 \\ ライス大学電気・コンピュータ学科 (米国テキサス州ヒューストン市)
}

\section{Magneto-Optical Spectroscopy of Semiconductors Using Terahertz Quantum Cascade Lasers}

\author{
Junichiro KONO \\ Department of Electrical and Computer Engineering, Rice University, Houston, Texas 77005, U.S.A.
}

(Received October 7, 2005)

\begin{abstract}
We have used quantum-cascade lasers operating at 4.7 THz, 3.5 THz, and $2.3 \mathrm{THz}$ to perform $\mathrm{THz}$ magnetooptical studies of semiconductors. We observed cyclotron resonance in InAs and InSb quantum wells from liquid-helium temperatures to room temperature. This represents the first spectroscopic application of $\mathrm{THz}$ quantum-cascade lasers. Results show that these compact lasers are convenient and reliable sources with adequate power and stability for this type of far-infrared magneto-optical study of solids. Their compactness promises interesting future applications in solid-state spectroscopy. As an example, the development of an ultracompact optically-detected $\mathrm{THz}$ resonance spectroscopy system will be described.
\end{abstract}

Key Words: Quantum cascade lasers, THz magneto-optical spectroscopy, Cyclotron resonance, Semiconductors

1.はじめに

過去数年の間，テラヘルツ帯域(周波数0.4-40 THz，波 長30-3000 $\mu \mathrm{m}$, 光子エネルギー0.4-40 MeV)において作動 する量子カスケードレーザーが開発された1-3)。これは, 高機能固体素子を欠き「テクノロジーギャップ」4)ともよば れる未開発周波数帯を埋めるための非常に画期的な進歩 である.このようなコンパクトな固体テラヘルツ光源に は様々なセンシングやイメージングの応用が期待されて いる5). 本稿では，テラヘルツ量子カスケードレーザーの 固体物性実験への応用の最初の例として，固体における 典型的な $\mathrm{THz}$ 励起の一つである半導体サイクロトロン共鳴 (CR)の実験について紹介する6).

\section{2. 量子カスケードレーザーの特徵}

中赤外領域で動作する量子カスケードレーザーの技術 は非常に発達しており, 例えばガスや化学物質の検知の 応用において $10^{-4}$ から $10^{-6}$ の高感度を達成している7-9). そ のような応用分野においては, 波長可変性, 高出力, お よび単一モード発振が不可欠である. 一方, 固体のテラ ヘルツ分光の応用においては, 狭い線幅はそれほど重要 ではない.なぜなら, 固体中での共鳴は原子・分子気体 中での共鳴に比べものすごく広い共鳴線幅を持っている からである．従って，波長掃引によるテラヘルツスペク トロスコピーを固体中で行掞うとすれば，まず不可能で あろうほど広い带域での波長連続可変性を要求される。 しかしながら, この問題は, 電場や磁場, 電圧, または
温度のような他の実験パラメーターをスキャンすること によって回避できる. 我々はテラヘルツ透過光強度を磁 場の関数として測定することにより, サイクロトロン共 鳴の実験を行った. 以下に示すように, テラヘルツカス ケードレーザーは，使いやすく，強度・波長の安定性も あり，また線形光実験を高い信号・ノイズ比で行うのに 十分なパワーを持つ。さらに，他のテラヘルッ光源・分 光器 (例えば, フーリ工変換赤外分光器 (FTIR), 自由電子 レーザー(FEL), 二酸化炭素レーザーポンプ分子ガスレー ザー, 差周波発生器, 光パラメトリック発振器) と比べて はるかにコンパクトであり，空間に制限があるような応 用においては有益である。

\section{3. 実験方法}

サイクロトロン共鳴は, 半導体のバンドパラメーター (特にバンド端での有効質量) を決定するための非常に便利 で有益な方法である10). また, キャリアの散乱確率, 電 子・フォノン相互作用, 様々な多体効果を調べるのにも 有用である. 入射光の波長または印加磁場の強度の関数 として試料を透過した電磁波を測定することによって共 鳴を検出する. 共鳴のエネルギーは, $\omega_{\mathrm{c}}=e B / m^{*}\left(\omega_{\mathrm{c}}\right.$ はサ イクロトロン周波数, $e$ は電子の電荷, $m^{*}$ は電荷キャリア の有効質量)で与えられ, 磁場Bに比例して増加する。典 型的な実験系では, 上述のTHz光源の一つと超伝導磁石を 組み合わせ，低温・強磁場下でTHz分光を行う.

我々は, 約 $4 \mathrm{~mW}$ の最大cwパワーで4.7テラヘルツ $(64$ $\mu \mathrm{m})$ や 2.3 $3 ヘ ル ッ ~(127 \mu \mathrm{m})$ の発振周波数を持つGaAs/ 
$\mathrm{AlGaAs} \mathrm{QCLs}{ }^{2)}$ を光源として用いた. $25 \%$ のン・オフ 比, $135 \mathrm{~Hz}$ の繰り返し周波数でパルス稼動した。試料はzcutクオーツ光学空 $(\mathrm{f} / 2.4)$ を持つ10テスラ超伝導磁石内に 置かれた. THzビームはパラボリックミラー対によって フォーカス・集光され, 最終的に液体へリウム温度のシ リコンボロメーターによって検出された，大気中での吸 収を防ぐため，光路内は乾燥した窒素でパージした。 レーザーの波長ドリフトは30秒間に約 $20 \mathrm{MHz}$ ，また，サ イクロトロン共鳴測定中の長期的波長ドリフトも小さ く, 重要ではなかった。短期の強度摇らぎは1秒の間に約 $0.5 \%$ あ゙あ, 長期の強度摇らぎは湿度の摇らぎ以外は観 測されなかった。試料としては以下の二つの異なる二次 元電子系を用いた：(1) $1.2 \times 10^{12} \mathrm{~cm}^{-2}$ の総電子密度と $120,000 \mathrm{~cm}^{2} / \mathrm{Vs}$ の移動度を持つ20周期InAs/AlSb多重量子井 戸，そして(2) $100,000 \mathrm{~cm}^{2} / \mathrm{Vs}$ の移動度をもつ単一 $30-\mathrm{nm}$ $\mathrm{InSb} / \mathrm{Al}_{0.09} \mathrm{In}_{0.91} \mathrm{Sb}$ 量子井戸.

\section{4. 実験結果}

Fig. 1は，60から300 Kの温度でのInAs量子井戸における $4.7 \mathrm{THz}$ ビームの透過の地盤依存性を示している. $1.5 \mathrm{~K} に$ おける共鳴磁場の光周波数依存性と, $4.7 \mathrm{THz}$ におけるサ イクロトロン質量の温度依存性は，それぞれFig. 2 (a), Fig. 2 (b)に示されている. Fig. 2 (a)における直線は1.51 $(\mathrm{T} / \mathrm{THz})$ の傾斜を持ち，有効質量 $0.042 m_{0}\left(m_{0}=9.1 \times 10^{-31}\right.$ $\mathrm{kg}$ ：真空での自由電子質量)に相当する. 8バンドk. pモデ ルに基づいたランダウ準位の計算およびシュブニコフ . ドハース振動から求められた電子密度から，4.7 THzにお ける共鳴は $(2, \uparrow) \rightarrow(3, \uparrow)$ の遷移として理解できる。

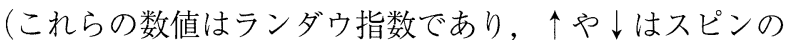
向きを表している). Fig. 2 (b)に示すように，観測された サイクロトロン質量は温度の上昇に伴い増加するが，こ れは理論から単純に予想される動きと全く逆である，バ ンドギャップは温度の上昇に伴い減少するので, 有効質

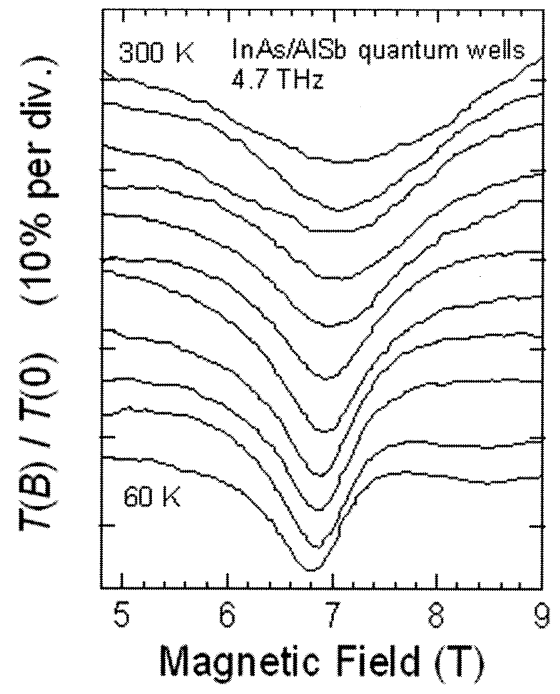

Fig. 1 Cyclotron resonance spectra for InAs/AlSb quantum wells at various temperatures $(60-300 \mathrm{~K})$, taken with a $4.7 \mathrm{THz}$ quantum cascade laser.
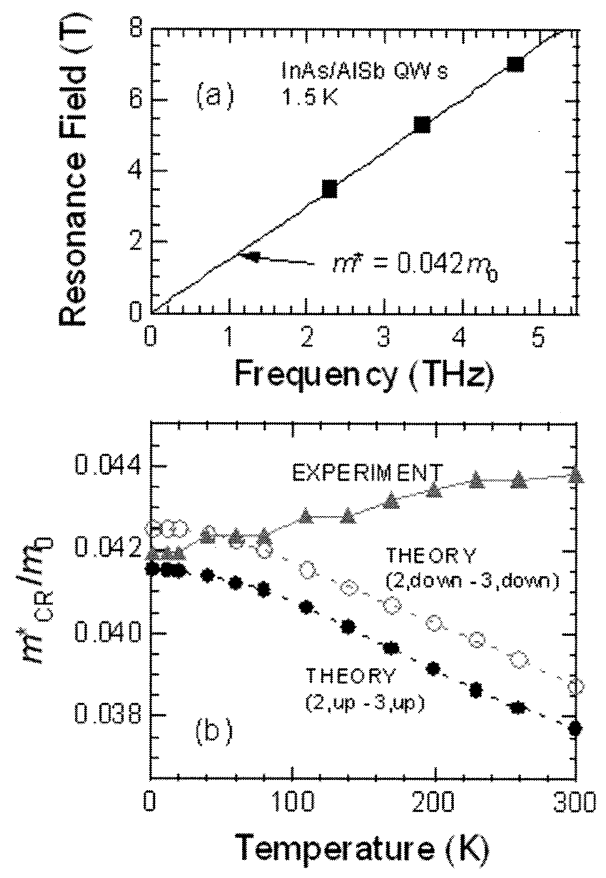

Fig. 2 (a) Resonance field as a function of photon frequency at $1.5 \mathrm{~K}$ for the InAs/AlSb quantum wells. The straight line has a slope of $1.51 \mathrm{~T} / \mathrm{THz}$, corresponding to an effective mass of $0.042 \mathrm{m0}$. (b) Cyclotron mass versus temperature at $4.7 \mathrm{THz}$ for the InAs/ AlSb quantum wells. The experimental mass (triangles) increases with increasing temperature, whereas the theoretical masses (open and filled circles) for two possible CR transitions show the opposite behavior.

量は伝導带と価電子帯の間の反発の増加のために減少す るべきである。この意外な温度依存性を強調するため に, Fig. 2 (b) に二つの理論曲線を示す。これらの曲線は それぞれ $(2, \uparrow) \rightarrow(3, \uparrow)$ と $(2, \downarrow) \rightarrow(3, \downarrow)$ の遷移に相 当しており，歪や量子閉じ込め，バンドギャップの温度 への依存を含む修正されたPidgeon-Brownモデル11)によっ て計算された。共鳴の線幅は高温度では明らかに幅が広 く,さらに高いランダウレベルでの遷移(例えば3から4)が 起き，高い質量に貢献するのももっともである。また， 他のバンドパラメター(特にいわゆる ‘F-パラメター’)の温 度依存性および温度に依存した電子・格子相互作用の効 果なども観測されるサイクロトロン質量に影響すること が考えれられる。これらを考慮に入れたランダウ順位の 計算は現在進行中である。

サイクロトロン共鳴における非線形現象 ${ }^{12-14)}$ を探索す るために，我々は次にテラヘルツ強度依存性を調べた。 InSb量子井戸に対する結果をFig. 3に示す。ここでは4.7

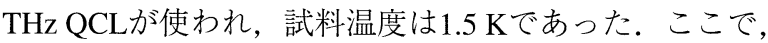
$\mathrm{InSb}$ の伝導帯の大きな非放物線性のために，スペクトルは $3.13 \mathrm{~T}$ と3.34 Tの二䇢所に共鳴を持つ。二つのデータは二 つの強度 (約 $50 \mu \mathrm{W} / \mathrm{cm}^{2}$ と約 $50 \mathrm{~mW} / \mathrm{cm}^{2}$ ) に対応するが，二 つとも全く同じであり，共鳴飽和のきざしはまったく見 えない。これは, 強度 $50 \mathrm{~mW} / \mathrm{cm}^{2}$ がまだサイクロトロン共 鳴飽和強度に満たないことを意味する。参考までに，バ ルク InSbのサイクロトロン共鳴の強度依存性においては, 


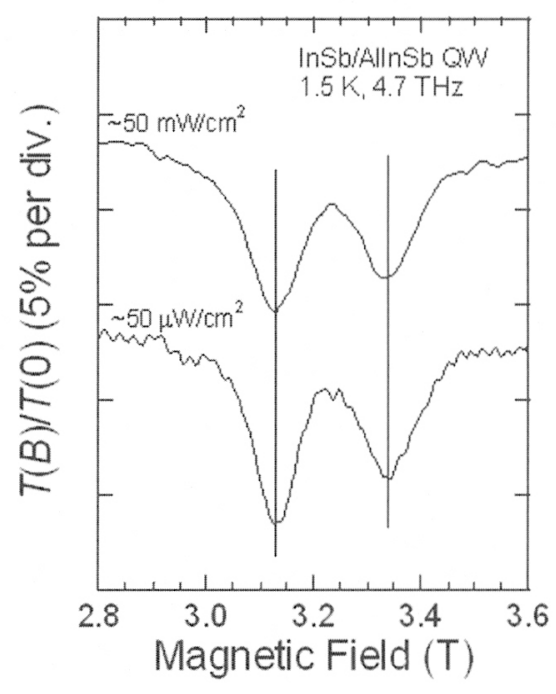

Fig. 3 Transmission as a function of magnetic field of an InSb/A10.09In0.91Sb quantum well. The QCL's wavelength is $64 \mu \mathrm{m}(4.7 \mathrm{THz})$, and the sample temperature is $1.5 \mathrm{~K}$.

飽和状態が約 $10^{-1} \mathrm{~W} / \mathrm{cm}^{2}$ で起こり始める事を示してい る14). THz非線型効果の研究のためにはさらに高強度の THz量子カスケードレーザーが必要である。

\section{5. 超小型光検知 $T \mathrm{~Hz}$ 共鳴システム}

最後に，我々は，量子カスケードレーザーのコンパク 卜さを最大に利用した超小型の光検知 THz共鳴 (OpticallyDetected THz Resonance: ODTR) システムを開発中である。 Fig. 4の写真を見てほしい. ODTR ${ }^{15)}$ では, THz共鳴は光ル ミネセンス (以下PL)の強度か偏光の変化として検出され る。典型的な半導体のPLは近赤外か可視の領域で発生す るので, THz共鳴を高感度の光検出器(例えば光電子増倍 管)で検知する事が出来, 結果的に従来のTHz分光に比べ てすぐれたS/N比を得ることができる，通常のODTRシス テムでは炭酸ガスレーザー励起分子ガスレーザー15)まな は自由電子レーザー16)を用いるが，我々はTHzソースとし てTHz QCLを使用している。Fig. 2 (左)のように，QCLを 直接サンプルホルダーに取り付け，レーザーと試料の間 の距離，したがって強度のロスを最小化する，QCLを冷 やすために別冷却器が必要ないことはいうまでもない。さ らに，試料にコンタクトをつけることにより，Fig. 2 (右) のように, ODTRのほかに, 磁場中電子輸送測定や光伝導 などの複数の実験を一つのサンプルで行う事が出来る.

\section{6. おわりに}

結論として, 我々は半導体に扮ける磁気光学スペクト ロコピーを行うために，テラヘルツ量子カスケードレー ザーを使用した。この新奇な光源は，既存の遠赤外レー ザーに比ベコンパクトで，コスト的にも安く，簡単に使 用できる、線形光学測定を高い信号・ノイズ比で行うの に十分なパワーを有し，そのコンパクトさは新しい応用 分野を期待させる。一例として，我々は目下，種々の超

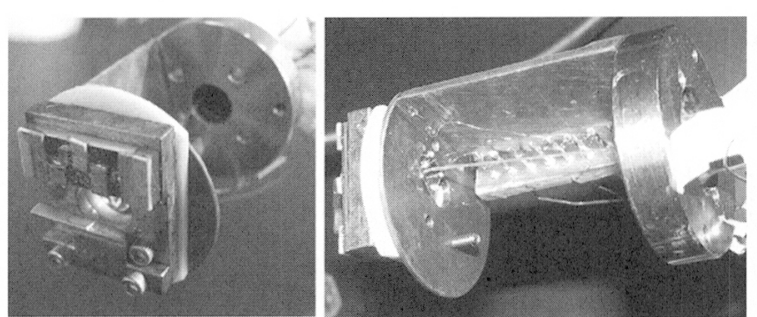

Fig. 4 (left) THz quantum cascade laser mounted on the bottom of the sample holder in a superconducting magnet. (right) Optical fiber touching the sample for maximum PL excitation/collection efficiency, together with electrical contacts for performing magneto-transport experiments.

伝導磁石中で使用できる超小型光検知 $\mathrm{THz}$ 共鳴システムを 開発中である。

\section{謝 辞}

この研究は，以下の人々と共同で行われた：D.C. Larrabee, G. A. Khodaparast, F. K. Tittel, M. Rochat, L. Ajili, J. Faist, H. Beere, E. Linfield, Y. Nakajima, M. Nakai, S. Sasa, M. Inoue, S. J. Chung, M. B. Santos, R. Srivastava, and X. Wang. 研究をサポートしてくれたNational Science Foundationに感 謝する。

\section{参考文献}

1) R. Koehler, A. Tredicucci, F. Beltram, H. E. Beere, E. H. Linfield, A. G. Davies, D. A. Ritchie, R. C. Iotti, and F. Rossi: Nature 417 (2002) 156.

2) M. Rochat, L. Ajili, H. Willenberg, J. Faist, H. Beere, G. Davies, E. Linfield, and D. Ritchie: Appl. Phys. Lett. 81 (2002) 1381.

3) B. S. Williams, H. Callebaut, S. Kumar, Q. Hu, and J. L. Reno: Appl. Phys. Lett. 82 (2003) 1015.

4) See, e.g., New Directions in Terahertz Technology, edited by J. M. Chamberlain and R. E. Miles (Kluwer Academic Publishers, Dordrecht, 1997).

5) See, e.g., Sensing with Terahertz Radiation, edited by D. M. Mittleman (Springer, Berlin, 2003).

6) D. C. Larrabee, G. A. Khodaparast, F. K. Tittel, J. Kono, M. Rochat, L. Ajili, J. Faist, H. Beere, E. Linfield, Y. Nakajima, M. Nakai, S. Sasa, M. Inoue, S. J. Chung, and M. B. Santos: Opt. Lett. 29 (2004) 122.

7) See, e.g., F. Capasso, C. Gmachl, D. L. Sivco, and A. Y. Cho: Phys. Today 55, p. 34, May 2002, and references cited therein.

8) A. A. Kosterev, R. F. Curl, F. K. Tittel, C. Gmachl, F. Capasso, D. L. Sivco, J. N. Baillargeon, A. L. Hutchinson, and A. Y. Cho: Optics Lett. 24 (1999) 1762.

9) A. A. Kosterev and F. K. Tittel: IEEE J. Quant. Electron. 38 (2002) 582.

10) J. Kono: in: Methods in Materials Research, eds. E. N. Kaufmann et al. (John Wiley \& Sons, New York, 2001) Unit 9b.2.

11) C. R. Pidgeon and R. N. Brown: Phys. Rev. 146 (1966) 575.

12) G. A. Rodríguez, R. M. Hart, A. J. Sievers, F. Keilmann, Z. Schlesinger, S. L. Wright, and W. I. Wang: Appl. Phys. Lett. 49 (1986) 458.

13) S. K. Singh, B. D. McCombe, J. Kono, S. J. Allen, Jr., I. Lo, W. C. Mitchel, and C. E. Stutz: Phys. Rev. B 58 (1998) 7286.

14) E. Gornik, T. Y. Chang, T. J. Bridges, V. T. Nguyen, J. D. McGee, and W. Müller: Phys. Rev. Lett. 40 (1978) 1151

15) J. Kono, S. T. Lee, M. S. Salib, G. S. Herold, A. Petrou, and B. D. McCombe: Phys. Rev. 52 (1995) R8654.

16) J. Cerne, J. Kono, M. S. Sherwin, M. Sundaram, A. C. Gossard, and G. E. W. Bauer: Phys. Rev. Lett. 77 (1996) 1131. 